Review

\title{
Cereal-Based Gluten-Free Food: How to Reconcile Nutritional and Technological Properties of Wheat Proteins with Safety for Celiac Disease Patients
}

\author{
Carmela Lamacchia ${ }^{1}$, Alessandra Camarca ${ }^{2}$, Stefania Picascia ${ }^{2}$, Aldo Di Luccia ${ }^{1}$ and \\ Carmen Gianfrani ${ }^{2,3, *}$
}

1 Department of Food Science, University of Foggia, Via Napoli 25, 71100 - Foggia, Italy. E-Mails: c.lamacchia@unifg.it (C.L.); a.diluccia@unifg.it (A.D.L.)

2 Institute of Food Sciences-CNR, Carmen Gianfrani, ISA-CNR, Via Roma 64, 83100 - Avellino, Italy; E-Mails: acamarca@isa.cnr.it (A.C.); s.picascia@isa.cnr.it (S.P.)

3 Institute of Protein Biochemistry-CNR, Via P. Castellino, 111, 80131 - Naples, Italy.

* Author to whom correspondence should be addressed; E-Mail: cgianfrani@isa.cnr.it; Tel.: +39-0825-299-411; Fax +39-0825-781-585.

Received: 11 November 2013; in revised form: 17 January 2014 / Accepted: 17 January 2014 / Published: 29 January 2014

\begin{abstract}
The gluten-free diet is, to date, the only efficacious treatment for patients with Celiac Disease. In recent years, the impressive rise of Celiac Disease incidence, dramatically prompted changes in the dietary habit of an increasingly large population, with a rise in demand of gluten-free products. The formulation of gluten-free bakery products presents a formidable challenge to cereal technologists. As wheat gluten contributes to the formation of a strong protein network, that confers visco-elasticity to the dough and allows the wheat flour to be processed into a wide range of products, the preparation of cereal-based gluten-free products is a somehow difficult process. This review focuses on nutritional and technological quality of products made with gluten-free cereals available on the market. The possibility of using flour from naturally low toxic ancient wheat species or detoxified wheat for the diet of celiacs is also discussed.
\end{abstract}

Keywords: Celiac Disease; cereals; wheat gluten; dough; immune toxicity 


\section{Introduction}

In the past 100 years, the human being has experienced a biological transformation with a speed greater than the trend of the last millennia. Over the past seventy years, the diet of Western man has been totally revolutionized: farm food, once characterized for being fresh and free of toxin residues, additives and preservatives, has been almost completely replaced by food products of an industrial chain that is, in the great majority of cases, oriented towards profit and the creation of induced needs. All this has radically changed, and still continues to change, the biological systems in humans leading to metabolic syndrome, allergies and intolerances, among both children and adults, in developed and developing countries.

In this context, in the last two decades, a series of epidemiologic studies have shown a particular increase in Celiac Disease (CD), a life-long intolerance to gluten proteins (the seed storage proteins) present in most cereals [1], both in the United States and Europe, and in developing countries [2,3]. In these subjects, the consumption of cereals containing gluten causes a chronic inflammatory process leading to lesions in the small intestine and a dysfunction in nutrient absorption [1]. The CD treatment, therefore, is based on a strict gluten-free diet throughout the patient's lifetime. Though this dietary regimen guarantees the full recovery of small intestine architecture and functions, for many patients it is strongly restrictive, especially for social events and during travelling. In addition, it is a great task for the food industry to provide safe food that partly resembles in taste and appearance pasta, bread and other baked goods. Furthermore, the nutritional importance of wheat proteins should not be underestimated, particularly in less developed countries where bread, noodles and other products (e.g., bulgur, couscous) may represent substantial diet components.

\section{Celiac Disease}

Celiac disease is the most common food induced enteropathy in humans. CD is strongly associated with particular HLA genotypes, as only individuals carrying the DQA1*0501 and DQB1*0201 (DQ2), or DQA1*0301 and DQB1*0302 (DQ8) alleles develop the disease. Gluten intolerance presents a large variety of symptoms including gastrointestinal and extra-intestinal manifestations, though in some patients, particularly of pediatric age, the disease is completely symptomless [4,5]. Typical clinical manifestations of CD include chronic diarrhea, weight loss and anemia, mainly caused by malabsorption, as a direct consequence of intestinal villous atrophy. However, a significant proportion of patients have "atypical" form, characterized by extra-digestive symptoms, including skin lesions, isolated hypertransaminasemia, bone pains and fractures, and infertility [6]. Several serological screening detecting the CD-associated anti-tissue transglutaminase (or anti-endomysium) IgA antibodies, and followed by endoscopy, have shown that approximately $1 \%$ of the general population have celiac disease [7,8]. However, Maki and co-workers found that the total prevalence of CD is even higher, reaching $1.99 \%$ in the Finnish population [9]. The wide spectrum of clinical manifestations, together with the absence of clear symptoms in some cases, could explain why the prevalence of CD is so underestimated. Regarding the pathogenic mechanisms, it is widely accepted that CD is an immune mediated disorder, in which intestinal CD4+ T cells, highly reactive to dietary gluten, have a pivotal role in disease pathogenesis [10]. In addition, recent studies have indicated the prominent role of both 
innate immune cells and adaptive CD8 $+\mathrm{T}$ cells in damaging the mucosal tissue $[10,11]$. To date, the only treatment for celiac disease patients is the lifelong complete exclusion of the gluten from the diet. With such a dietary restriction, clinical symptoms, serological markers, and duodenal mucosa histology normalize [12], however gluten reactive $\mathrm{T}$ cells remain in the small intestine of patients on gluten-free diet, and re-exposure to the gluten results in immune activation and in mucosal damage. As a consequence, gluten avoidance is strongly recommended; nevertheless, dietary compliance is imperfect in a large number of patients for several reasons, including the need of flavor and palatability of gluten-free cereal-based food [13].

\section{Gluten, the Dough "Treasure"}

Gluten is one of the earliest protein fractions described by chemists, (a first description by Beccari was in 1728), and it is defined as the "cohesive, visco-elastic proteinaceous material" that remains when wheat dough is washed to remove starch granules and water soluble constituents $[14,15]$. Gluten is formed by storage proteins necessary for plant germination [16]. In these respects, the wheat storage proteins may not differ much from those of other cereals $[14,17]$, however, the distinctive feature that makes wheat unique is, precisely, the visco-elasticity of gluten. When the grain is milled and mixed with water, storage proteins form a dough, capable of retaining gas bubbles. These properties make wheat suitable for the preparation of a great diversity of food products, including breads, noodles, pasta, and cookies, and it has been the subject of extensive attention by the food industry. Of note, in order to meet the consumer needs, food industries have made in the last fifty years an indiscriminate use of wheat gluten even in food that is naturally devoid, as sauces, chips, cold cuts.

Gluten contains hundreds of proteins, which are present either as monomers or as oligo- and polymers, linked by inter-chain disulphide bonds [15,17], and characterized by high contents of glutamine and proline (namely prolamins), and by low contents of charged amino acids. The new system of classification, based on the availability of complete amino acid sequences, divided the gluten proteins in three broad groups: sulphur-rich (S-rich), sulphur-poor (S-poor), and high molecular weight (HMW) prolamins ([18], Figure 1). Traditionally, gluten proteins have been divided according to their solubility in alcohol-water solutions (e.g., 60\% ethanol), as the soluble gliadins and the insoluble glutenins [19]. These properties are largely determined by the inter-chain disulphide bonds, with the glutenins consisting of disulphide-stabilized polymers. Reduction of these inter-chain bonds allows the separation of the glutenin subunits into low molecular weight (LMW) and high molecular weight (HMW) groups (Figure 2). In contrast, the alcohol-soluble gliadin fraction consists mainly of monomeric proteins, which either lack cysteine ( $\omega$-gliadins), or have only intra-chain disulphide bonds ( $\alpha$-type and $\gamma$-type gliadins) (Figure 2). However, small amounts of polymers related to the glutenins are also present in the gliadin fraction. These appear to differ from the alcohol-insoluble glutenins, as they have lower $M_{\mathrm{r}} \mathrm{s}$ and higher contents of LMW subunits [20-22]. 
Figure 1. Schematic representation of types and peculiarities of wheat gluten proteins (gliadins and glutenins-GS; modified from [17]).

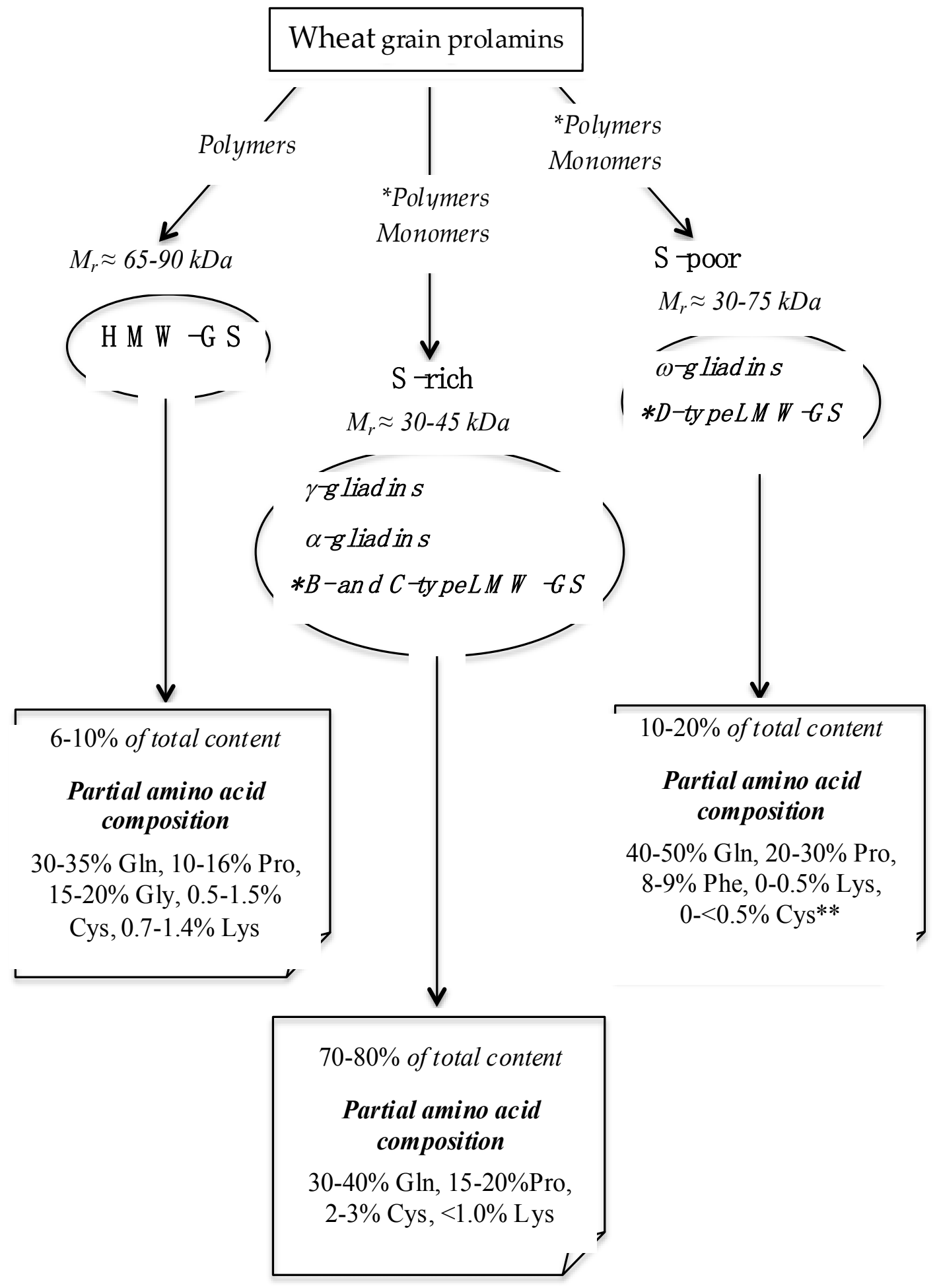

*C-type LMW subunits are essentially polymeric forms of $\alpha$ - and $\gamma$-gliadins and D-type LMW subunits polymeric $\omega$-gliadins. The B-type LMW subunits constitute a discrete group of S-rich prolamins.

**Cys is present in D-type LMW subunits, but not $\omega$-gliadins. 
Figure 2. Gluten proteins: fractions and technological properties [23].

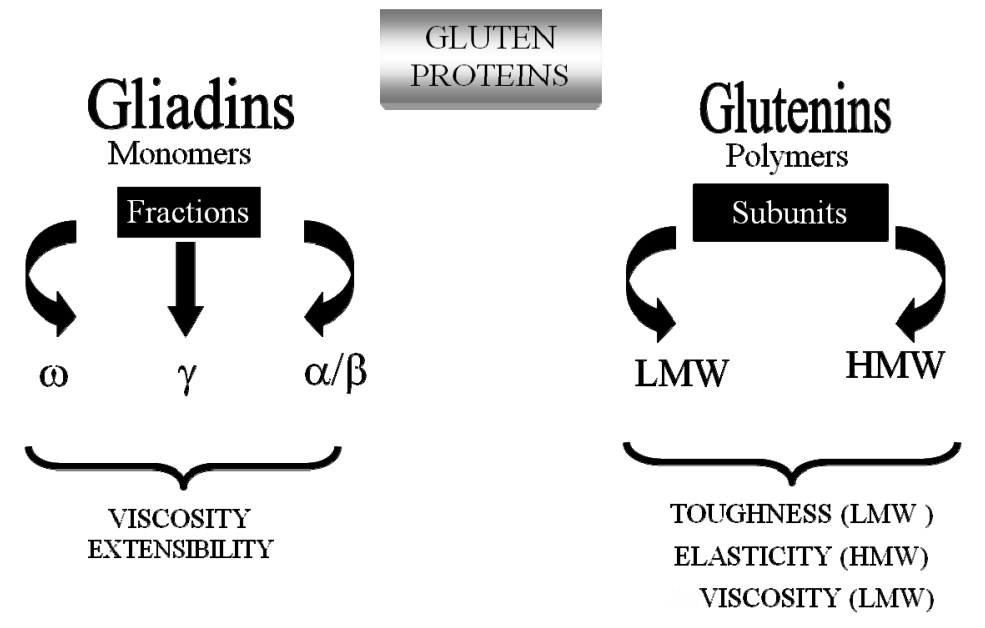

Both fractions are important contributors to the rheological properties of dough (Figure 2), though their functions are divergent. Hydrated gliadins have little elasticity and are less cohesive than glutenins, and contribute mainly to the viscosity and extensibility of the dough. In contrast, hydrated glutenins are both cohesive and elastic and are responsible for dough strength and elasticity [24,25]. A proper mixture of both fractions is essential for the quality of the end product. However, of particular importance are the glutenin polymers, and it is well established that strong (i.e., highly visco-elastic) doughs contain high proportions of HMW glutenin polymers [24]. Numerous studies are consistent with the hypothesis that the HMW subunits form an elastomeric polymer network which provides a "backbone" for interactions with other glutenin subunits and with gliadins (Figure 3) [26,27]. There is no doubt that this network is mainly stabilized by inter-chain disulphide bonds [28,29]. Additional covalent bonds formed during dough making are tyrosine-tyrosine and thiyl-tyrosine crosslinks between gluten proteins [30-32]. However, the covalent structure of the gluten network is superimposed by non-covalent bonds (hydrogen bonds, ionic bonds, hydrophobic bonds) [33].

Figure 3. A structural model for wheat gluten in which the HMW subunits provide a disulphide-bonded backbone that interacts with other gluten proteins by disulphide bonds (LMW subunits) and non-covalent interactions (gliadins) (modified from [26]).

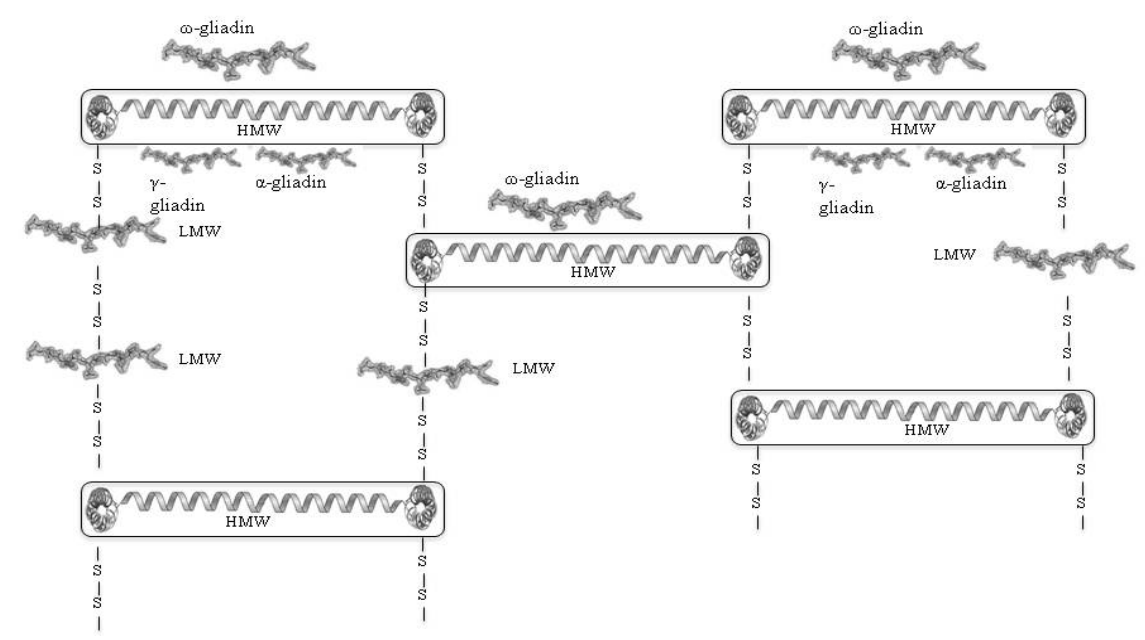




\section{Formulation and Nutritional Value of Gluten-free Products}

The food not allowed in the gluten free diet include: (a) all types of bread and food prepared with wheat flour, including kamut and spelt, rye, barley, triticale, or with ingredients from these flours; (b) food that contains wheat, or derivatives of gluten used as thickeners, such as hot dogs, salad dressing, sauces, canned, some types of cheese and cold cuts; (c) medicinal products that use gluten as binder in the pills or tablets.

Though from a nutritional point of view, gluten exclusion does not entail particular problems, being a mixture of proteins with low nutritional and biological value, the gluten-free diet creates enormous limitations, above all in the social activities related to food. In addition, this dietary therapy has, often low content of vitamins and ions, such as vitamins B and D, calcium, iron, zinc, and magnesium, as well as fiber [34-36]. Furthermore, one of the major risks is the risk to develop obesity and diseases related to metabolic syndrome [37]. However, the high technological value renders gluten almost indispensable in baked products, and its replacement, as structure-building protein, presents a major technological challenge for the food industry. Although many advances have been made in the preparation processes of gluten-free products, using starches, hydrocolloids, gums and novel ingredients [38], many gluten-free industrial products available on the market exhibit a low nutritional quality, poor mouth feel or flavor [39] and, no less important, are particularly expensive. As a consequence, the research interest to develop gluten-free products has significantly increased in recent years. The pilot study by Rotsch [40] showed that bread could be prepared from starch and gel-forming substances, since starch, combined with water, at a temperature included between 60 and $80{ }^{\circ} \mathrm{C}$, increases in volume, in a sort of swelling (a process called gelatinization) [41-43]. This process increases the product consistency by mimicking the gluten viscoelastic properties. Thickeners and gums/hydrocolloids, derived from various seeds, fruits, or plant extracts, could be also added in these formulations to improve water retention, texture and appearance properties [44-47]. Among different types of flours, present on the market and rich in starch, rice and corn flour are the best suited to the gelatinization process. These starches, are polysaccharides composed of amylose and amylopectin, present in the original product in the percentages equal to $20 \%-30 \%$ and $70 \%-80 \%$, respectively.

The amylose is a linear polymer of glucose in which the glucose units are held together by $\alpha(1 \rightarrow 4)$ bonds, whilst the amylopectin is a branched polymer of glucose, similar to amylose, structured with side chains that are grafted every 24-30 glucose units through $\alpha(1 \rightarrow 6)$ bonds. Amylopectin is the most responsible for the gelatinization of starch granules in the presence of water and heat. During this process a fraction of both amylopectin and amylose goes into solution, however, the starch gelatinization is inversely proportional to the amylose content $[48,49]$. From a nutritional perspective, the more starch is gelatinized (because of its reduced amount of amylose), the more it is hydrolysable by alpha-amylase, with an increase of the glycemic index [50,51]. In contrast, with a greater amylose content, the gelatinization process is reduced, as well as the glycemic index. Gluten-free food prepared with corn and rice starch have a high glycemic index [52,53] and increase the risk to develop metabolic syndromes in celiac patients [54,55]. In fact, it is well known from epidemiological studies that the daily consumption of high glycemic index food is correlated with the risk to develop cardiovascular disease, obesity and diabetes [56-60]. Furthermore, the use of palm oil, cream powder, 
microencapsulated high-fat powder, and low-fat dairy powders [39,40], aimed to improve the palatability of cereal-based gluten-free products, renders these products highly caloric.

\section{Recent Advances in Formulation of Cereal-Based Gluten-Free Food}

In addition to the high glycemic index and caloric density of cereal-based gluten-free food, these products generally are not enriched/fortified, so that, they may not contain the same levels of nutrients, as the natural wheat grains. Therefore, uncertainty still exists whether celiac patients compliant with gluten-free therapy have a nutritionally balanced diet. Grehn et al. screened the intake of nutrients and foods of 49 adults diagnosed with coeliac disease and following a strict gluten-free diet [61]. They had a lower intake of fibre when compared to a control group on a normal diet. In their studies with coeliac adolescents, Mariani et al. [62] concluded that adherence to a gluten-free diet worsens the nutritionally unbalanced diet in adolescents, as it has been thereafter confirmed by Thompson et al. [63]. For these reasons several studies investigated the preparation of a new generation of cereal-based gluten-free food. The enrichment of baked products with dietary fibres and devoid of gluten has been the goal of various technologist teams. Gallagher et al. incorporated inulin ( $8 \%$ inclusion level) into a wheat starch-based gluten-free formulation [64]. Inulin is a non-digestible polysaccharide that is classified as a dietary fibre. It also acts as a prebiotic by stimulating the growth of "healthy" bacteria in the colon [65]. When added to wheat bread, inulin improves loaf volume, increases dough stability and produces a uniform, and finely grained, crumb texture [66].

Gambus et al. replaced corn starch with amaranth flour to enhance the protein and fibre contents of gluten-free breads [67]. At a 10\% replacement level, protein and fibre levels increased by $32 \%$ and $152 \%$ respectively, whilst sensory quality was unaffected. Taylor and Parker discussed the use of quinoa in the production of enriched gluten-free bakery goods [68]. Both quinoa and amaranth are dicotyledonous species that are not related to the actual cereals (monocotyledons), such as wheat, barley and rice. They are also called pseudocereals, since these species produce small seeds that resemble those of cereals. The grain of pseudocereals does not contain gluten proteins but it is rich in proteins with high biological value (albumins and globulins) and contains carbohydrates that can be considered nutraceuticals, as they have cholesterol- [69,70] and glycemic-lowering effects, and induce a reduction of free fatty acids [52]. Importantly, the total absence of immune toxicity of amaranth storage protein for celiacs patients has been demonstrated [71], and several studies were carried out in order to improve the structural properties of quinoa and amaranth as ingredients for bread, pasta and crackers [72-74].

\section{Nutritional Quality of Wheat Flour: Advantages in Introducing a Cereal-Based Gluten-Free Food in Diet of Celiacs}

The therapy with gluten-free products, besides the risk of nutrient deficiency and metabolic syndrome, as described above, entails the difficulty of maintaining the cure over time. Reduced palatability and taste of gluten-free food create enormous limitations in the diet of patients. To solve these issues, numerous studies are currently devoted to the use of in vitro detoxified flour or flour from ancient wheat cultivars, in the formulation of pasta and baked goods. 


\subsection{Nutritional and Health Properties of Hexaploid and Tetraploid Wheat}

Worldwide, the number of people who eat wheat for a substantial part of their diet reaches several billions. Because of the high content of starch, (about $60 \%-70 \%$ of the whole grain and $65 \%-75 \%$ of white flour) wheat is often considered no more than a source of calories. Despite its relatively low protein content (usually $8 \%-15 \%$ ), wheat still provides as much protein for human and livestock nutrition as the total soybean crop (as calculated in reference [75]. However, the lysine content of wheat is low and varies significantly from grain to flour [15]. Grain of high protein content has very low content of lysine approximately $30 \mathrm{mg} \mathrm{g}^{-1}$ protein [76]. Wheat is a source of minerals such as $\mathrm{Zn}$ (20-30 mg Kg$\left.{ }^{-1}\right)$ and $\mathrm{Fe}\left(30-36 \mathrm{mg} \mathrm{Kg}^{-1}\right)$, contributing to $44 \%$ of the daily intake of iron (15\% in bread), and $25 \%$ of the daily intake of zinc (11\% in bread) in the UK [77] Wheat is also a source of selenium which varies widely from about $10 \mu \mathrm{g} \mathrm{Kg}^{-1}$ to over $2000 \mu \mathrm{g} \mathrm{Kg}^{-1}$ (FAO/WHO, 2001; [78]). The concentration of selenium in wheat is largely determined by the availability of this element in the soil. Wheat produced in Western Europe may contain only one-tenth of the selenium that is present in wheat grown in North America. Wheat also contains a range of components with established health benefits that are concentrated, or solely located, in the bran. In addition, the following components are either present in low amounts, or completely absent, and with a large variation in their concentrations:

- lignans, a group of polyphenols with phytoestrogen-like activity, present at levels up to $10 \mu \mathrm{g} \mathrm{g}^{-1}$ in wholemeal wheat and almost $20 \mu \mathrm{g} \mathrm{g}^{-1}$ in the bran [79];

- phenolic acids that in wholemeal range up to almost $1200 \mu \mathrm{g} \mathrm{g}^{-1}$ [80]. They represent, quantitatively, the major group of phytochemicals in the wheat grain and are derivatives of either hydroxibenzoic acid or hydroxycinnamic acid. Epidemiological studies indicate that phenolic acids have a number of health benefits which may relate to their antioxidant activity; furthermore, a high correlation between the total antioxidant activities of grain and their phenolic acid contents has been reported $[81,82]$;

- folates that in wholemeal varied from 364 to $774 \mathrm{ng} \mathrm{g}^{-1}$ dry weight in winter wheats and from 323 to $741 \mathrm{ng} \mathrm{g}^{-1}$ dry weight in spring wheats, and positively correlated with the bran yield [83];

- dietary fibre derives from polymers of wheat endosperm cell wall: they are constituted mainly by arabinoxylans (approximately 70\%) and (1-3) (1-4) $\beta$-D-glucans (approximately 20\%). The arabinoxylans are present in both soluble and insoluble forms, being the former considered to have health benefits $[84,85]$. However, insoluble fibre may also favour the delivering phenolic antioxidants into the colon, with a reduction of colon-rectal cancer risk [86]. Gebruers et al. showed wide variation in the contents of total and water-extractable arabinoxylans in both white flour and bran fractions [87]. Similarly Ordaz-Ortiz et al. showed variation from $0.26 \%$ to $0.75 \%$ dry weight in the content of water-extractable arabinoxylan in 20 French wheat cultivars and from $1.66 \%$ to $2.87 \%$ dry weight in total arabinoxylans [88].

\subsection{Ancient Wheats}

Triticum monococcum, was the first wheat to be cultivated by man and is a diploid species characterized by the presence of the AA genome. Due to the simplicity of its genome, Triticum monococcum has 
attracted the interest of the scientific community on nutritional and health aspects in relation to celiac disease. If we consider, in fact, that for each genome (AA, BB and DD) there are dozens of genes coding for prolamins in wheat caryopses, it is evident that in Triticum monococcum the mere presence of the AA genome encodes for a reduced variety of gluten proteins (and of potential immune toxic peptides). Recent evidence shows that prolamins of some Triticum monococcum cause a reduced inflammatory effect in celiac patients [89-92], particularly for the inability to activate the innate branch of immune cells [89], or to induce apoptosis of enterocytes [93]. The reduced, or absent, toxicity of Triticum monococcum prolamins can then be interpreted in two ways, namely via $(i)$ a low presence of toxic peptides; (ii) an abundant presence of protective sequences. However, other in vitro and in vivo studies have warned about the safety of some monococcum cultivars for celiac patients [94,95], thus suggesting that the immune toxicity for celiacs might strictly depend on the specific Triticum monococcum varieties.

The search of naturally detoxified, or less toxic, ancient grains is of great interest for their potential use in the general diet to prevent disease in those individuals at high risk to develop gluten intolerance.

Regarding the technological properties, though some studies have considered Triticum monococcum not suitable for bread and pasta production [96,97], it has been demonstrated that the aptitude to bread-making is extremely different and depends on the specific varieties analyzed [98,99]. Studies carried out at an industrial level have shown that pasta made with 100\% of Triticum monococcum flour has very low loss of starch during cooking comparable to that made from durum wheat semolina [23]. These findings on the bread- and pasta-making aptitude of Triticum monococcum flours are encouraging, and indicate a real chance to select for ancient varieties with superior technological characteristics and reduced toxicity for celiacs.

\subsection{Detoxification of Wheat Gluten}

Numerous studies are currently devoted to prepare pasta and baked goods made from wheat flours modified in order to eliminate, or reduce, the immune toxicity of gluten proteins (detoxification process).

A first method, using endopeptidase of bacterial origin during the preparation of wheat flour dough, results in the complete degradation of gluten peptides including those that are strongly immune toxic for celiacs [100]. Such an approach, carrying out a total destruction of the gluten network, reduces the technological properties (viscoelasticity) of dough and, consequently, of pasta or baked goods, unless the flour is integrated with structuring agents, as pre-gelatinized starch, emulsifiers or hydrocolloids.

Another method to detoxify gluten proteins uses the specific transdamidation of toxic epitopes done by the tissue-transglutaminase of microbial origin (Streptomyces mobaraensis) in the presence of lysine methyl ester [101]. This method has the great advantage of blocking the immunogenicity of $\mathrm{T}$ cell epitopes (as demonstrated in an in vitro assays using intestinal $\mathrm{T}$ cell from celiacs), and more importantly, it keeps intact the gluten network and preserves the technological properties of the flour. Furthermore, this procedure uses an enzyme largely employed in the food industry for improving the texture of foods. A preliminary 90-days trial made with CD subjects in remission consuming bread slices with transamidated gluten indicated that only a subgroup of celiacs exhibited clinical symptoms compared to subjects consuming the toxic gluten [102]. The researchers have now implemented the 
transamidation reaction in order to reach protection in the great majority of $\mathrm{CD}$ volunteers that eat detoxified wheat flour.

\section{Conclusions}

The gluten proteins contained in wheat flour are crucial during the bread and pasta making process, since they confers to the dough its viscosity and elasticity. In addition, wheat flour provides to foodstuffs important nutritional components, including dietary fibre, vitamins, and minerals. These properties account for wheat being cultivated by man in such enormous quantities throughout the world. However, gluten proteins are also responsible for a very common, and in most cases very severe, intolerance in a large number of individuals. To date the only safe and efficacious therapy for people with celiac disease is the long-life avoidance of gluten from the diet.

The replacement of the unique technological properties of wheat gluten represents the major task of industry for providing high quality gluten-free foods, such as pasta, bread and baked products, in terms of structure, loss of starch during cooking, and optimal cooking time.

Nutritional studies on people with CD on a gluten-free diet revealed several nutrient deficiencies, particularly of vitamins and minerals, as well as an increased of obesity risk, this latter due to the high glycemic index of the gluten-free diet. However, despite the numerous studies, it has not yet been possible to offer celiac patients an alternative diet therapy, based on high nutritional and tasty cereals that are naturally gluten-free. Foodstuffs made with technologically detoxified wheat flour, or with wheat varieties with naturally low content of toxic gluten sequences, or more suitable to gastrointestinal enzymatic degradation, would be a much-desired dietary therapeutic alternative. An extensive production of foodstuffs made with detoxified wheat flour that could be commonly consumed not only by those people suffering gluten intolerance, but also by the rest of the population could be envisaged; the large diffusion of such products could have the goal, in a totally innovative way, of reducing the immune sensitization to gluten and, likely, decreasing the incidence of celiac disease.

\section{Acknowledgments}

This work has been partly supported by a grant from the Italian Ministry of Research PRIN 2009- "Interaction between innate and adaptive immunity in the pathogenesis of CD"-CUP: E61J11000300001, and by "ProAliFun" project P.O.N Ricerca e Competitività 2007-2013.

\section{Conflicts of Interest}

The authors declare no conflict of interest.

\section{References}

1. Shuppan, D.; Tennis, M.D.; Kelly, C.P. Celiac disease: Epidemiology, pathogenesis, diagnosis, and nutritional management. Nutr. Clin. Care 2005, 8, 54-69.

2. Hill, I.; Fasano, A.; Schwartz, R.; Counts, D.; Glock, M.; Horvath, K. Prevalence of celiac disease in at risk groups of children in United States. Pediatr. Res. 2000, 136, 86-90. 
3. Barada, K.; Abu Daya, H.; Rostami, K.; Catassi, C. Celiac disease in the developing world. Gastrointest. Endosc. Clin. N. Am. 2012, 22, 773-796.

4. Paparo, F.; Petrone, E.; Tosco, A.; Maglio, M.; Borrelli, M.; Salvati, V.M.; Miele, E.; Greco, L.; Auricchio, S.; Troncone, R. Clinical, HLA, and small bowel immunohistochemical features of children with positive serum antiendomysium antibodies and architecturally normal small intestinal mucosa. Am. J. Gastroenterol. 2005, 100, 2294-2298.

5. Biagi, F.; Trotta, L.; Alfano, C.; Balduzzi, D.; Staffieri, V.; Bianchi, P.I.; Marchese, A.; Vattiato, C.; Zilli, A.; Luinetti, O.; et al. Prevalence and natural history of potential celiac disease in adult patients. Scand. J. Gastroenterol. 2013, 48, 537-542.

6. Di Sabatino, A.; Corazza, G.R. Coeliac disease. Lancet 2009, 373, 1480-1493.

7. White, L.E.; Merrick, V.M.; Bannerman, E.; Russell, R.K.; Basude, D.; Henderson, P.; Wilson, D.C.; Gillett, P.M. The rising incidence of celiac disease in scotland. Pediatrics 2013, 132, 924-931.

8. Kang, J.Y.; Kang, A.H.; Green, A.; Gwee, K.A.; Ho, K.Y. Systematic review: Worldwide variation in the frequency of coeliac disease and changes over time. Aliment. Pharmacol. Ther. 2013, 38, 226-459.

9. Lohi, S.; Mustalahti, K.; Kaukinen, K.;, Laurila, K.; Collin, P.; Rissanen, H.; Lohi, O.; Bravi, E.; Gasparin, M.; Reunanen, A.; et al. Increasing prevalence of coeliac disease over time. Aliment. Pharmacol. Ther. 2007, 26, 1217-1225.

10. Meresse, B.; Malamut, G.; Cerf-Bensussan, N. Celiac disease: An immunological jigsaw. Immunity 2012, 36, 907-919.

11. Mazzarella, G.; Stefanile, R.; Camarca, A.; Giliberti, P.; Casentini, E.; Marano, C.; Iaquinto, G.; Giardullo, N.; Auricchio, S.; Sette, A.; et al. Gliadin activates HLA Class-I restricted CD8+ T cells in celiac disease intestinal mucosa and induces the enterocyte apoptosis. Gastroenterology 2008, 134, 1017-1027.

12. Biagi, F.; Bianchi, P.I.; Marchese, A.; Trotta, L.; Vattiato C.; Balduzzi, D.; Brusco, G.; Andrealli, A.; Cisarò, F.; Astegiano, M.; et al. A score that verifies adherence to a gluten-free diet: A cross-sectional, multicentre validation in real clinical life. Br. J. Nutr. 2012, 108, 1884-1888.

13. Mazzeo, T.; Brambillasca, F.; Pellegrini, N.; Valmarana, R.; Corti, F.; Colombo, C.; Agostoni, C. Evaluation of visual and taste preferences of some gluten-free commercial products in a group of celiac children. Int. J. Food Sci. Nutr. 2014, 65, 112-116.

14. Shewry, P.R. Wheat. J. Exp. Bot. 2009, 60, 1537-1553.

15. Wieser, H. Chemistry of gluten proteins. Food Microb. 2007, 24, 115-119.

16. Shewry, P.R. The synthesis, processing, and deposition of gluten proteins in developing grain. Cereal Food World 1999, 44, 587-589.

17. Shewry, P.R.; Halford, N.G. Cereal seed storage proteins: Structures, properties and role in grain utilization. J. Exp. Bot. 2002, 53, 947-958.

18. Shewry, P.R.; Tatham, A.S. The prolamin storage proteins of cereal seeds: Structure and evolution. Biochem. J. 1990, 267, 1-12.

19. Osborne T.B. The vegetable proteins. J. Soc. Chem. Ind. 1924, 43, 440.

20. Bietz, J.A.; Wall, J.S. Isolation and characterization of gliadin-like subunits from glutenin. Cereal Chem. 1973, 50, 537-547. 
21. Bietz, J.A.; Wall, J.S. Identity of high molecula weight gliadin and ethanol-soluble glutenin subunits of wheat: Relation to gluten structure. Cereal Chem. 1980, 57, 415-421.

22. Kanazawa, H.; Yonezawa, D. Studies on polypeptide composition of low molecular weight glutenin. J. Agr. Chem. Soc. Jpn. 1973, 47, 17-22.

23. Lamacchia, C.; La Gatta, B.; Schiavulli, A.; Pati, S.; Petrella, G.; di Luccia, A. Triticum monococcum species, a chance for pasta business. Prof. Pasta 2013, April-June,12-27.

24. Field, J.M; Shewry, P.R.; Miflin, B.J. Solubilization and characterization of wheat gluten proteins; correlations between the amount of aggregated proteins and baking quality. J. Sci. Food Agric. 1983, 34, 370-377.

25. Payne, P.I. Genetics of wheat storage and the effect of allelic variation on breadmaking quality. Annu. Rev. Plant Phys. 1987, 38, 141-153.

26. Shewry, P.R.; Popineau, Y.; Lafiandra, D.; Belton, P. Wheat glutenin subunits and dough elasticity: Findings of the EUROWHEAT project. Trends Food Sci. Technol. 2001, 11, 433-441.

27. Lindsay, M.P.; Skerritt, J.H. The glutenin macropolymer of wheat flour doughs: Structure-function perspective. Trends Food Sci. Tech. 1999, 10, 247-253.

28. Shewry, P.R.; Tatham, A.S. Disulphide bonds in wheat gluten proteins. J. Cereal Sci. 1997, 25, 207-227.

29. Wieser, H. The Use of Redox Agents. In Bread Making-Improving Quality; Cauvain, S.P., Ed.; Woodhead Publishing Ltd.: Cambridge, UK, 2003; pp. 424-446.

30. Tilley, K.A.; Benjamin, R.E.; Bagorogoza, K.E.; Okot-Kotber, B.M.; Prakash, O.; Kwen, H. Tyrosine cross-links: Molecular basis of gluten structure and function. J. Agric. Food Chem. 2001, 49, 2627-2632.

31. Lamacchia, C.; di Luccia, A.; Baiano, A.; Gambacorta, G.; La Gatta, B.; Pati, S.; La Notte, E. Changes in pasta proteins induced by drying cycles and their relationship to coking behavior. J. Cereal Sci. 2007, 46, 58-63.

32. Lamacchia, C.; Baiano, A.; Lamparelli, S.; Terracone, C.; Trani, A.; Di Luccia, A. Formation of polymeri proteins during pasta-making in barley and semolina mixture and predictions of its effects on cooking behavior and acceptability. Food Chem. 2011, 129, 319-328.

33. Wieser H.; Bushuk W.; Mac Ritchie F. The Polymeric Glutenins. In Gliadin and Glutenin: The Unique Balance of Wheat Quality. St. Paul American Association of Cereal Chemistry; Wrigley, C., Bekes, F., Bushuk, W., Eds.; American. Association of Cereal Chemists: St. Paul MN, USA, 2006; pp. 213-240.

34. Shepherd, S.J.; Gibson, P.R. Nutritional inadequacies of the gluten-free diet in both recently-diagnosed and long-term patients with celiac disease. J. Hum. Nutr. Diet. 2013, 26, 349-358.

35. Hallert, C.; Grant, C.; Grehn, S.; Grännö, C.; Hultén, S.; Midhagen, G.; Ström, M.; Svensson, H.; Valdimarsson, T. Evidence of poor vitamin status in coeliac patients on a gluten-free diet for 10 years. Aliment. Pharmacol. Ther. 2002, 16, 1333-1339.

36. Wierdsma, N.J.; van Bokhorst-de van der Schueren, M.A.; Berkenpas, M.; Mulder, C.J.; van Bodegraven, A.A. Vitamin and mineral deficiencies are highly prevalent in newly diagnosed celiac disease patients. Nutrients 2013, 5, 3975-3992. 
37. Kabbani, T.A.; Gldberg, A.; Kelly, C.P.; Pallav, K.; Tariq, S.; Peer, A.; Hansen, J.; Dennis, M.; Leffler, D.A. Body mass index and risk of obesity in celiac disease treated with the gluten-free diet. Aliment. Pharmacol. Ther. 2012, 35, 723-729.

38. Zannini, E.; Jones, J.M.; Renzetti, S.; Arendt, E.K. Functional replacements for gluten. Annu. Rev. Food Sci. Technol. 2012, 3, 227-245.

39. Arendt, E.K.; O’Brien, C.M.; Schober, T.; Gormley, T.R.; Gallagher, E. Development of gluten-free cereal products. Farm Food 2002, 12, 21-27.

40. Rotsch, A. Chemische und technische Untersuchungen an künstlichen Teigen. Brot. Gebaeck. 1954, 8, 129.

41. Anon. Hydrocolloids improve shelf-life and moisture retention of shelf-stable bagels. Food Technol. 2002, 56, 50.

42. Laureys, C. A natural choice for texture: Rice derivatives. Food Technol. Eur. 1996, 3, 68-71.

43. Ward, F.M.; Andon, S.A. Hydrocolloids as film formers, adhesives and gelling agents for bakery and cereal products. Cereal Food World. 2002, 47, 52-55.

44. Chillo, S.; Suriano, N.; Lamacchia, C.; Del Nobile, M.A. Effects of additives on the rheological and mechanical properties of non-conventional fresh handmade tagliatelle. J. Cereal Sci. 2009, 49, 163-170.

45. Gan, J.; Rafael, L.G.B.; Cato, L.; Small, D.M. Evaluation of the Potential of Different Rice Flours in Bakery Formulations. In Proceedings of the 51st Australian Cereal Chemistry Conference, Cooge, New South Wales, 9-13 September 2001; pp. 309-312.

46. Norton, I.T.; Foster, T.J. Hydrocolloids in Real Food Systems. In Gums and Stabilisers in the Food Industry II; Royal Society of Chemistry: Cambridge, UK, 2002; pp. 187-200.

47. Ranhorta, G.S.; Loewe, R.J.; Puyat, L.V. Preparation and fortification of soy-fortified gluten-free bread. J. Food Sci. 1975, 40, 62-64.

48. Frederickson, H.; Silverio, J.; Andersson, R.; Eliasson, A.C.; Aman, P. The influence of amylose and amylopectin characteristics on gelatinisation and retrogradation properties of different starches. Carbohydr. Polym. 1998, 35, 119-134.

49. Sasaki, T.; Yasui, T.; Matsuki, J. Effect of amylose content on gelatinisation, retrogradation, and pasting properties from waxy and nonwaxy wheat and their F1 seeds. Cereal Chem. 2000, 77, 58-63.

50. Holm, J.; Lundquist, I.; Bjorck, I.; Eliasson, A.C..; Asp, N.G. Degree of starch gelatinization, digestion rate of starch in vitro, and metabolic response in rats. Am. J. Clin. Nutr. 1988, 47, 1010-1016.

51. Bird, A.R.; Lopez-Rubio, A.; Shrestha, A.K.; Gidley, M.J. Resistant Starch in vitro and in vivo: Factors Determining Yield, Structure and Physiological Relevance. In Modern Biopolymer Science; Academic Press, Elsevier Inc: London, UK, 2009; pp. 449-510.

52. Berti, C.; Riso, P.; Monti, L.D.; Porrini, M. In vitro starch digestibility and in vivo glucose response of gluten free foods and their counterparts. Eur. J. Nutr. 2004, 43, 198-204.

53. Eliasson, A.; Larsson, K. Cereals in Breadmaking; Marcel Dekker: NY, USA, 1993.

54. Scaramuzza, A.E.; Mantegazza, C.; Bosetti, A.; Zuccotti, G.V. Type 1 diabetes and celiac disease: The effects of gluten free diet on metabolic control. World J. Diabetes 2013, 4, 130-134. 
55. Norsa, L.; Shamir, R.; Zevit, N.; Verduci, E.; Hartman, C.; Ghisleni, D.; Riva E.; Giovannini, M. Cardiovascular disease risk factor profiles in children with celiac disease on gluten free diets. World J. Gastroenterol. 2013, 19, 5658-5664.

56. Livesey, G.; Taylor, R.; Livesey, H.; Liu, S. Is there a dose-response relation of dietary glycemic load to risk of type 2 diabetes? Meta-analysis of prospective cohort studies. Am. J. Clin. Nutr. 2013, 97, 584-596.

57. Liu, S.; Willett, W.C., Stampfer, M.J.; Hu, F.B.; Franz, M.; Sampson, L.; Hennekens, C.H.; Manson, J.E.A. prospective study of dietary glycemic load, carbohydrate intake, and risk of coronary heart disease in US women. Am. J. Clin. Nutr. 2000, 71, 1455-1461.

58. Brand-Miller, J.C.; Holt, S.H.; Pawlak, D.B.; McMillan, J. Glycemic index and obesity. Am. J. Clin. Nutr. 2013, 76, 281S-285S.

59. Tosi, E.A.; Ciappini, M.C.; Masciarelli, R. Utilisation of whole amaranthus (Amaranthus cruentus) flour in the manufacture of biscuits for coeliacs. Alimentaria 1996, 34, 49-51.

60. Ferrara, P.; Cicala, M.; Tiberi, E.; Spadaccio, C.; Marcella, L.; Gatto, A.; Calzolari, P.; Castellucci, G. High fat consumption in children with celiac disease. Acta Gastroenterol. Belg. 2009, 72, 296-300.

61. Grehn, S.; Fridell, K.; Lilliecreutz, M.; Hallert, C. Dietary habits of Swedish adult coeliac patients treated by a gluten-free diet for 10 years. Scand. J. Food Nutr. 2001, 45, 178-182.

62. Mariani, P.; Viti, M.G.; Montuori, M.; La Vecchia, A.; Cipolletta, E.; Calvani, L.; Bonamico, M. The gluten-free diet: A nutritional risk factor for adolescents with celiac disease? J. Pediatr. Gastroenterol. Nutr. 1998, 27, 519-523.

63. Thompson, T. Thiamin, riboflavin, and niacin contents of the gluten-free diet: Is there cause for concern? J. Am. Diet. Assoc. 1999, 99, 858-862.

64. Gallagher, E.; Polenghi, O.; Gormley, T.R. Novel Rice Starches in Gluten-Free Bread. In Proceedings of the International Association of Cereal Chemists Conference, Budapest, Hungary, May 26-29, 2002; pp. 24-26.

65. Gibson, G.R.; Roberfroid, M.B. Dietary modulation of the human colonic microbiota: Introducing the concept of prebiotics. J. Nutr. 1995, 125, 1401-1412.

66. Anon, E. Inulin: Added value. Eur. Bak.1999, 32, 40-44.

67. Gambus, H.; Gambus, F.; Sabat, R. The research on quality improvement of gluten-free bread by amaranthus flour addition. Zywnosc 2002, 9, 99-112.

68. Taylor, J.R.N.; Parker, M.L. Quinoa. In Pseudocereals and Less Common Cereals, Grain Properties and Utilization Potential; Springer: Verlag, Berlin, 2002; pp. 93-122.

69. Danz, R.A.; Lupton, J.R. Physiological effects of dietary amaranth (Amarantus cruentus) on rats. Cereal Food World 1992, 37, 489-494.

70. Qureshi, A.A.; Lehamn, J.W.; Peterson, D.M. Amaranth and its oil inhibit cholesterol biosynthesis in 6-week-old female chickens. J. Nutr. 1996, 126, 1972-1978.

71. Bergamo, P.; Maurano, F.; Mazzarella, G.; Iaquinto, G.; Vocca, I.; Rivelli, A.R.; de Falco, E.; Gianfrani, C.; Rossi, M. Immunological evaluation of the alcohol-soluble protein fraction from gluten-free grains in relation to celiac disease. Mol. Nutr. Food Res. 2011, 55, 1266-1270.

72. Alvarez-Jubete, L.; Arendt, E.K.; Gallagher, E. Nutritive value of pseudocereals and their increassing use as functional glutenfree ingredients. Trends Food Sci. Tech. 2010, 21, 106-113. 
73. Lamacchia, C.; Chillo, S.; Lamparelli, S.; Suriano, N.; Del Nobile, M.A. Amaranth, quinoa and oat doughs: Mechanical and rheological behaviour, polymeric size distribution and extractability. J. Food Eng. 2010, 96, 97-106.

74. Caperuto, L.; Amaya-Farfan, J.; Camargo, C. Performance of quinoa (Chenopodium quinoa Willd.) flour in the manufacture of gluten free spaghetti. J. Sci. Food Agric. 2000, 81, 95-101.

75. Shewry, P.R. Seed Proteins. In Seed Technology and Its Biological Basis; Black, M., Bewley, J.D., Eds.; Sheffield Academic Press: Sheffield, UK, 2000; pp. 42-84.

76. Mossè, J.; Huet, J.C. Aminoacid composition and nutritional score for ten cereals and six legumes or oilseeds: Causes and ranges of variation according to species and to seed nitrogen content. Sci. Aliment. 1990, 10, 151-173.

77. Andersson, H.; Nävert, B.; Bingham, S.A.; Englyst H.N.; Cummings, J.H. The effects of breads containing similar amounts of phytate but different amounts of wheat bran on calcium, zinc and iron balance in man. Br. J. Nutr. 1983, 50, 503-510.

78. Combs, G.F. Selenium in global food systems. Br. J. Nutr. 2001, 85, 517-547.

79. Nagy-Scholz, E.; Ercsey, K. Lignan Analysis of Cereal Samples by GC/MS Method. In The HEALTHGRAIN Methods Book; Shewry, P.R., Ward, J., Eds.; St. Paul, MN USA, 2009.

80. Li, L.; Shewry, P.R.; Ward, J.L. Phenolic acids in wheat varieties in the HEALTHGRAIN diversity screen. J. Agric. Food Chem. 2008, 56, 9732-9739.

81. Drankham, K.; Carter, J.; Madl, R.; Klopfenstein, C.; Padula, F.; Lu, Y.; Warren, T.; Schmitz, N.; Takemoto, D.J. Antitumor activity of wheats with high orthophenolic content. Nutr. Cancer 2003, 47, 188-194.

82. Wende, L.; Fang, S.; Shancheng, S.; Corke, H.; Beta, T. Free radical scavenging properties and phenolic content of Chinese black-grained wheat. J. Agric. Food Chem. 2005, 53, 8533-8536.

83. Piironen, V.; Edelmann, M.; Kariluoto, S.; Bedo, Z. Folate in wheat genotypes in the HEALTHGRAIN diversity screen. J. Agric. Food Chem. 2008, 56, 9726-9731.

84. Moore, M.A.; Beom Park, C.; Tsuda, H. Soluble and insoluble fiber influences on cancer development. Crit. Rev. Oncol. Hematol. 1998, 27, 229-242.

85. Lewis, S.J.; Heaton, K.W. The metabolic consequences of slow colonic transit. Am. J. Gastr. 1999, 94, 2010-2016.

86. Vitaglione, P.; Napolitano, A.; Fogliano, V. Cereal dietary fibre: A natural functional ingredient to deliver phenolic compounds into the gut. Trends Food Sci. Tech. 2008, 19, 451-463.

87. Gebruers, K.; Domez, E.; Boros, D.; Fras, A.; Dynkowska, W.; Bedo, Z.; Rakszegi, M.; Delcour, J.A.; Courtin, C.M. Variation in the content of dietary fiber and components thereof in wheats in the HEALTHGRAIN diversity screen. J. Agric. Food Chem. 2008, 56, 9740-9749.

88. Ordaz-Ortiz, J.J.; Devaux, M.F.; Saulnier, L. Classification of wheat varieties based on structural features of arabinoxylans as revealed by endoxylanase treatment of flour and grain. J. Agric. Food Chem. 2005, 53, 8349-8356.

89. Gianfrani, C.; Maglio, M.; Rotondi Aufiero, V.; Camarca, A.; Vocca, I.; Iaquinto, G.; Giardullo, N.; Pogna, N.; Troncone, R.; Auricchio, S.; et al. Immunogenicity of monococcum wheat in celiac disease patients. Am. J. Clin. Nutr. 2012, 96, 1339-1345. 
90. De Vincenzi, M.; Luchetti, R.; Giovannini, C.; Pogna, N.E.; Saponaro, C.; Galterio, G.; Gasbarrini, G. In vitro toxicity testing of alcohol-soluble proteins from diploid wheat Triticum monococcum in celiac disease. J. Biochem. Toxicol. 1996, 11, 313-318.

91. Lundin, K.E.; Sollid, M.N. Mapping of gluten T-cell epitopes in the bread wheat ancestors: Implication for celiac diseases. Gastroenterology 2005, 128, 393-401.

92. Pizzuti, D.; Buda, A.; D’Odorico, A.; D’Inca, R.; Chiarelli, S.; Curioni, A.; Martines, D. Lack of intestinal mucosal toxicity of Triticum monococcum in celiac disease patients. Scand. J. Gastroenterol. 2006, 41, 1305-1311.

93. Vincentini, O.; Maialetti, F.; Gazza, L.; Silano, M.; Dessì, M.; De Vincenzi, M.; Pogna, N.E. The environmental factors of celiac disease: Cytotoxicity of hulled species Triticum monococcum, Triticumturgidum ssp dicoccum and T. aestivum ssp spelta. J. Gastroenterol. Hepatol. 2007, 22, 1861-1822.

94. Vaccino, P.; Becker, H.A.; Brandolini, A.; Salamini, F.; Kilian, B. A catalogue of Triticum monococcum genes encoding toxic and immunogenic peptides for celiac disease patients. Mol. Genet. Genomics. 2009, 281, 289-300.

95. Suligoj, T.; Gregorini, A.; Colomba, M.; Ellis, H.J.; Ciclitira, P.J. Evaluation of the safety of ancient strains of wheat in coeliac disease reveals heterogeneous small intestinal $\mathrm{T}$ cell responses suggestive of coeliac toxicity. Clin. Nutr. 2013, 32, 1043-1049.

96. Brandolini, A.; Marturini, M.; Plizzari, L.; Hidalgo, J.C.; Pompei, C.; Hidalgo, A. Chimical and technological properties of Triticum monococcum, Triticum turgidum and Triticum aestivum. Tec. Molit. Int. 2008, 59, 85-93.

97. D'Egidio, M.G.; Nardi, S.; Vallega, V. Grain, flour and dough characteristics of selected strains of diploid wheats Triticum monococcum L. Cereal Chem. 1993, 70, 298-303.

98. Corbellini, M.; Empilli, S.; Vaccino, P.; Brandolini, A.; Borghi, B.; Heun, M.; Salamini, F. Einkorn characterizationfor bread and cookie production in relation to protein subunit composition. Cereal Chem. 1999, 76, 727-733.

99. Borghi, B.; Castagna, R.; Corbellini, M.; Heun, M.; Salamini, F. Breadmaking quality of einkorn wheat (Triticum monococcum ssp. monococcum). Cereal Chem. 1996, 73, 208-214.

100. Rizzello, C.G.; de Angelis, M.; di Cagno, R.; Camarca, A.; Silano, M.; Losito, I.; de Vincenzi, D.; de Bari, M.D.; Palmisano, F.; Maurano, F.; et al. Highly efficient gluten degradation by lactobacilli and fungal proteases during food processing: New perspectives for Celiac Disease. Appl. Environ. Microbiol. 2007, 73, 4499-4507.

101. Gianfrani, C.; Siciliano, R.A.; Facchiano, A.M.; Camarca, A.; Mazzeo, M.F.; Costantini, S.; Salvati, V.M.; Maurano, F.; Mazzarella, G.; Iaquinto, G.; et al. Transamidation inhibits the intestinal immune response to gliadin in vitro. Gastroenterology 2007, 133, 780-789.

102. Mazzarella, G.; Salvati, V.M.; Iaquinto, G.; Stefanile, R.; Capobianco, F.; Luongo, D.; Bergamo, P.; Maurano, F.; Giardullo, N.; Malamisura, B.; et al. Reintroduction of gluten following flour transdamidation in adult celiac patients: A randomized, controlled clinical study. Clin. Dev. Immunol. 2012, 2012, 329150.

(C) 2014 by the authors; licensee MDPI, Basel, Switzerland. This article is an open access article distributed under the terms and conditions of the Creative Commons Attribution license (http://creativecommons.org/licenses/by/3.0/). 